\title{
The Association Between Obesity and Weight Loss Intention Weaker Among Blacks and Men than Whites and Women
}

\author{
Shervin Assari ${ }^{1,2} \cdot$ Maryam Moghani Lankarani ${ }^{2}$
}

Received: 31 January 2015 /Revised: 1 April 2015 / Accepted: 23 April 2015 /Published online: 15 May 2015

(C) W. Montague Cobb-NMA Health Institute 2015

\begin{abstract}
Introduction Although obesity is associated with weight loss intention, the magnitude of this association may differ across various populations. Using a nationally representative data of the USA, this study tested the variation of the association between obesity and weight loss intention based on race and gender.

Methods Data came from the National Survey of American Life (NSAL), 2001-2003, which enrolled 5810 nationally representative sample of adults (3516 African-Americans, 1415 Caribbean Blacks, and 879 non-Hispanic Whites). Socio-demographics, body mass index (BMI), and weight loss intention were measured. We fitted logistic regression models in the pooled sample with weight loss intention as the outcome, obesity $(\mathrm{BMI}>30)$ as the predictor, while the effect of covariates was controlled. To test our moderation hypotheses, we entered race $\times$ obesity and gender $\times$ obesity interactions to the model. Results Although the association between obesity and weight loss intention was significant among both race and gender groups, the magnitude of the association between obesity and weight loss intention was larger for women than men and Whites than Blacks. This finding suggests that individuals with obesity have less intention for weight loss if they are Black or men. Conclusion The link between obesity and weight loss intention depends on race and gender. Weight loss intention may
\end{abstract}

Shervin Assari

assari@umich.edu

1 Department of Psychiatry, University of Michigan, 4250 Plymouth Rd., Ann Arbor 48109-2700, MI, USA

2 Center for Research on Ethnicity, Culture and Health, School of Public Health, University of Michigan, 2847 SPH I, 1415 Washington Heights, Ann Arbor, MI 48109-2029, USA not increase in response to obesity among Blacks and men, compared to Whites and women. Healthy weight programs in the USA may benefit from tailoring based on race and gender.

Keywords Obesity $\cdot$ Weight loss intention $\cdot$ Race $\cdot$ Ethnic groups $\cdot$ Gender

\section{Introduction}

In a dose-dependent fashion, obesity increases the risk of cardiovascular disease and premature death [1]. Time lived with obesity increases the risk of cardiovascular mortality, independent of body mass index (BMI) [2]. Obesity increases risk of hypertension [3], diabetes [4], metabolic syndrome [5], and stroke [6]. Health care cost attributable to obesity has exceeded the expenditures attributed to smoking and problem drinking [7]. Compared to those with normal weight, individuals with obesity use more physician visits, spend more time in the hospital, use medications, and miss more work days $[8,9]$.

Obesity is a major contributor to racial health disparities in the USA [10]. Compared to non-Hispanic Whites, Blacks are $50 \%$ more likely to be obese, while the additional risk is $80 \%$ for Black women. This figure suggests that four out of five Black women are overweight or obese [11].

Although weight loss intention has a distribution in the general population [12], very few community-based studies have focused on determinants intention for weight loss at the population level [13]. Design and implementation of healthy weight programs, however, require knowledge about factors associated with intention for weight loss [14]. Communitybased research on social, psychological, and biological correlates of weight loss intention will improve the efficacy of healthy weight programs among populations, including minority groups $[15,16]$. Despite the literature suggesting that 
obesity [17], perceived obesity [15], race [18-21], and gender $[22,23]$ influence weight control intention [15], our knowledge is very limited on the contextual effects of race and gender on the association between weight and intention for weight loss.

In the United States, race, ethnicity, and gender shape correlates of obesity [30, 31]. Race and gender may also determine the links between weight, perceived weight, and intention to control weight. In that study, perceived weight seemed to mediate the association between actual weight and the intention to lose weight among White women and Black men, but not White men or Black women [24].

In response to the knowledge gap on the role of gender and race on the link between obesity and weight loss intention, the current study aimed to investigate if the link between obesity and weight loss intention is different across groups based on race and gender. To provide results generalizable to the USA, this study used data from the National Survey of American Life (NSAL), a nationally representative survey of Blacks in America [25].

\section{Methods}

The National Survey of American Life (NSAL) was completed between February 2001 and June 2003. The study protocol was approved by the Institutional Review Board of the University of Michigan, Ann Arbor. All participants gave consent for participation.

\section{Participants}

The NSAL included non-Hispanic Whites and Blacks. Our study included 5810 individuals including 3516 African-Americans, 1415 Caribbean Blacks, and 879 non-Hispanic Whites.

The NSAL sampling was a national household probability sample of individuals 18 years and older [25, 26]. AfricanAmericans and Whites were residents of either large cities or other urban and rural areas; however, Caribbean Blacks were sampled from large cities only.

\section{Interview}

Data was collected through face-to-face computer-assisted (86\%) or telephone (14\%) interview. Interviews lasted an average of $140 \mathrm{~min}$. All interviews were performed in English. The final response rate was $72.3 \%$ overall.

\section{Measures}

Socio-demographics including age, race, gender, employment status, education level, and country region were measured.

Obesity BMI was calculated based on self-reported weight and height, which is shown to be highly correlated with BMI based on direct measures of height and weight [27]. This approach may result in some underestimation of weight and overestimation of height [28], leading to low estimates of overweight and obesity [29]. BMI was dichotomized to healthy weight (BMI between 18.5 and 24.9)/ overweight (BMI between 25.0 and 29.9), versus any level of obesity, composed of class I (BMI between 30.0 and 34.9), class II (BMI between 35.0 and 39.9), or class III (BMI greater than 40.0$)$ of obesity [30, 31].

Weight Loss Intention The main outcome in this study was intention for weight loss, measured by the following single item measure: Are you currently trying to lose weight? Responses included yes, no, and don't know.

\section{Statistical Analysis}

Stata 13.0 was used for data analysis. For univariate analysis, weight-adjusted survey proportions and their $95 \%$ confidence intervals were reported. Subpopulation commands were used for data analysis. Multiple logistic regressions were used for multivariable analysis, by considering intention for weight loss as outcome, obesity (BMI $>40)$ as predictor, and race and gender as moderators. Model I did not include any interaction term. Models II and III included interactions between obesity $\times$ gender and obesity $\times$ race, respectively. Model IV included both interactions simultaneously. Adjusted odds ratio (OR) and $95 \%$ confidence interval (CI) were reported. $P$ values less than .05 were considered statistically significant.

\section{Results}

A total of 5810 adults (3516 African-Americans, 1415 Caribbean Blacks, and 879 non-Hispanic Whites) were entered into this study. Compared to men, women reported higher intention for weight loss. Compared to Blacks, Whites also reported higher intention to lose weight (Table 1).

\section{Model I}

Based on model I, obesity, female gender, and high education were positively associated with intention to lose weight, while being Black was associated with lower weight loss intention (Table 2).

\section{Model II}

Based on model II, obesity and high education were positively associated with intention to lose weight, while being Black was associated with lower intention to lose weight. This model suggested that the effect of obesity on intention to lose weight was higher among women than men; however, gender lost its main effect on the outcome (Table 3). 
Table 1 Body mass index and intention to lose weight among Caribbean Black, African-American, and White men and women

\begin{tabular}{|c|c|c|c|c|c|c|c|c|c|c|c|c|}
\hline & \multicolumn{4}{|c|}{ Caribbean Black } & \multicolumn{4}{|c|}{ African-Americans } & \multicolumn{4}{|c|}{ Non-Hispanic Whites } \\
\hline & \multicolumn{2}{|c|}{ Women } & \multicolumn{2}{|l|}{ Men } & \multicolumn{2}{|c|}{ Women } & \multicolumn{2}{|l|}{ Men } & \multicolumn{2}{|c|}{ Women } & \multicolumn{2}{|l|}{ Men } \\
\hline & $\%$ & $95 \% \mathrm{CI}$ & $\%$ & $95 \% \mathrm{CI}$ & $\%$ & $95 \% \mathrm{CI}$ & $\%$ & $95 \% \mathrm{CI}$ & $\%$ & $95 \% \mathrm{CI}$ & $\%$ & $95 \% \mathrm{CI}$ \\
\hline \multicolumn{13}{|l|}{ Obesity } \\
\hline Overweight & 36.4 & $(32.9-39.9$ & 40.6 & $(35.6-45.6)$ & 27.8 & $(26.0-29.6)$ & 29.7 & $(26.5-32.9)$ & 46.0 & $(38.9-53.1)$ & 37.1 & $(29.7-44.6)$ \\
\hline Obesity class I & 32.2 & $(27.9-36.5)$ & 40.6 & $(32.9-48.2)$ & 30.8 & $(28.5-33.1)$ & 40.8 & $(38-43.5)$ & 23.1 & $(15.5-30.6)$ & 40.1 & $(34.3-45.9)$ \\
\hline Obesity class II & 16.2 & $(12.7-19.7)$ & 12.8 & $(5.7-19.8)$ & 22.5 & $(20.4-24.6)$ & 18.9 & $(16.6-21.1)$ & 17.5 & $(14.0-21.0)$ & 17.5 & $(12.1-22.8)$ \\
\hline Obesity class III & 9.3 & $(5.3-13.4)$ & 5.5 & $(1.1-9.9)$ & 11.0 & $(9.3-12.7)$ & 6.6 & $(5.3-8)$ & 8.8 & $(5.6-12.0)$ & 3.8 & $(1.6-5.9)$ \\
\hline \multicolumn{13}{|c|}{ Weight control intention } \\
\hline No & 47.1 & $(40.1-54.1)$ & 73.3 & $(61.4-85.2)$ & 48.7 & $(45.5-51.9)$ & 67.8 & $(64.9-70.7)$ & 47.0 & $(42.052 .1)$ & 62.6 & $(58.9-66.3)$ \\
\hline Yes & 52.9 & $(45.9-59.9)$ & 26.7 & $(14.8-38.6)$ & 51.3 & $(48.1-54.5)$ & 32.2 & $(29.3-35.1)$ & 53.0 & $(47.958 .0)$ & 37.4 & $(33.7-41.1)$ \\
\hline
\end{tabular}

\section{Model III}

Based on model III, obesity, female gender, and high education were positively associated with intention to lose weight, while the effect of obesity on intention to lose weight was smaller for Blacks than Whites. Being Black lost its main effect on intention to lose weight in this model (Table 4).

\section{Model IV}

Obesity and high education were associated with higher intention to control weight, while race and gender did not have main effects on intention to control weight. Region was also not linked to the outcome. Based on this model, the effect of

Table 2 Summary of regression model I without any interaction terms on weight loss intention

\begin{tabular}{llllr}
\hline & Odds ratio & {$[95 \% \mathrm{CI}]$} & $P$ value \\
\hline Obesity (BMI>30) $^{\text {a }}$ & 4.740 & 3.816 & 5.888 & $<0.001$ \\
Blacks $^{\mathrm{a}}$ & 0.831 & 0.698 & 0.990 & 0.038 \\
Female $^{\mathrm{b}}$ & 1.768 & 1.505 & 2.077 & $<0.001$ \\
Age & 0.999 & 0.994 & 1.005 & 0.843 \\
Education $^{\mathrm{c}}$ & & & & \\
$\quad 12$ years & 1.421 & 1.130 & 1.788 & 0.003 \\
$\quad 13-15$ years & 1.900 & 1.476 & 2.445 & $<0.001$ \\
$\quad 16$ years or more & 2.425 & 1.809 & 3.251 & $<0.001$ \\
Region $* * * *$ & & & & \\
$\quad$ Midwest & 1.144 & 0.914 & 1.431 & 0.235 \\
$\quad$ South & 1.106 & 0.926 & 1.321 & 0.261 \\
$\quad$ West & 1.035 & 0.656 & 1.634 & 0.881 \\
Intercept & 0.121 & 0.086 & 0.171 & $<0.001$ \\
\hline
\end{tabular}

${ }^{\text {a }}$ Reference group; Whites

${ }^{\mathrm{b}}$ Reference group; Whites

${ }^{\mathrm{c}}$ Reference group; 11 years or less

${ }^{\mathrm{d}}$ Reference group; northeast obesity on intention to control weight was larger among women than men and smaller among Blacks than Whites (Table 5).

\section{Discussion}

Based on the current study, race and gender change the magnitude of the association between obesity and the weight loss intention in the USA. Obesity may result in lower levels of weight loss intention among Blacks and men.

Similar to the literature, women in this study were more likely to identify themselves as overweight and are more

Table 3 Summary of regression model II with the interaction term between gender and obesity on weight loss intention

\begin{tabular}{|c|c|c|c|c|}
\hline \multirow[b]{2}{*}{ Obesity } & \multirow{2}{*}{$\begin{array}{l}\text { Odds ratio } \\
6.986\end{array}$} & \multicolumn{2}{|c|}{$[95 \% \mathrm{CI}]$} & \multirow{2}{*}{$\begin{array}{c}P \text { value } \\
<0.001\end{array}$} \\
\hline & & 4.956 & 9.847 & \\
\hline Blacks $^{\mathrm{a}}$ & 0.830 & 0.695 & 0.992 & 0.041 \\
\hline Female $^{\mathrm{b}}$ & 1.138 & 0.862 & 1.503 & 0.358 \\
\hline Age & 0.999 & 0.994 & 1.004 & 0.775 \\
\hline \multicolumn{5}{|l|}{ Education $^{c}$} \\
\hline 12 years & 1.426 & 1.132 & 1.795 & 0.003 \\
\hline $13-15$ years & 1.914 & 1.483 & 2.471 & $<0.001$ \\
\hline 16 years or more & 2.400 & 1.773 & 3.249 & $<0.001$ \\
\hline \multicolumn{5}{|l|}{ Region $^{\mathrm{d}}$} \\
\hline Midwest & 1.144 & 0.916 & 1.429 & 0.232 \\
\hline South & 1.110 & 0.930 & 1.325 & 0.243 \\
\hline West & 1.034 & 0.653 & 1.638 & 0.884 \\
\hline \multicolumn{5}{|l|}{ Obesity\# Female } \\
\hline 0\#Female & 1.927 & 1.358 & 2.734 & $<0.001$ \\
\hline Intercept & 0.168 & 0.122 & 0.231 & $<0.001$ \\
\hline
\end{tabular}

${ }^{a}$ Reference group; Whites

${ }^{\mathrm{b}}$ Reference group; Whites

${ }^{\mathrm{c}}$ Reference group; 11 years or less

${ }^{\mathrm{d}}$ Reference group; northeast 
Table 4 Summary of regression model III with the interaction term between race and obesity on weight loss intention

\begin{tabular}{llllr}
\hline & Odds ratio & {$[95 \% \mathrm{CI}]$} & $P$ value \\
\hline Obesity (BMI>30) & 3.764 & 2.542 & 5.575 & $<0.001$ \\
Blacks $^{\mathrm{a}}$ & 1.117 & 0.797 & 1.567 & 0.515 \\
Female $^{\mathrm{b}}$ & 1.767 & 1.504 & 2.076 & $<0.001$ \\
Age & 0.999 & 0.994 & 1.005 & 0.835 \\
Education $^{\mathrm{c}}$ & & & & \\
$\quad$ 12 years & 1.416 & 1.118 & 1.793 & 0.004 \\
$\quad 13-15$ years & 1.908 & 1.482 & 2.455 & $<0.001$ \\
$\quad 16$ years or more & 2.411 & 1.786 & 3.256 & $<0.001$ \\
Region & & & & \\
$\quad$ Midwest & 1.133 & 0.911 & 1.410 & 0.256 \\
$\quad$ South & 1.109 & 0.931 & 1.320 & 0.242 \\
$\quad$ West & 1.039 & 0.654 & 1.651 & 0.870 \\
Obesity\# Blacks & 0.642 & 0.421 & 0.979 & 0.040 \\
Intercept $^{\text {d }}$ & 0.130 & 0.089 & 0.189 & $<0.001$ \\
\hline
\end{tabular}

${ }^{\text {a }}$ Reference group; Whites

${ }^{\mathrm{b}}$ Reference group; Whites

${ }^{\mathrm{c}}$ Reference group; 11 years or less

${ }^{\mathrm{d}}$ Reference group; northeast

likely to report intention to lose weight $[32,33]$. Women report higher motivation to lose weight possibly due to their higher perceived societal pressure to be thin and general concerns with their appearance. This is in line with the

Table 5 Summary of regression model IV with two interaction terms between gender $\times$ obesity and race $\times$ obesity on weight loss intention

\begin{tabular}{|c|c|c|c|c|}
\hline \multirow[b]{2}{*}{ Obesity (BMI>30) } & \multirow{2}{*}{$\begin{array}{l}\text { Odds ratio } \\
5.541\end{array}$} & \multicolumn{2}{|c|}{$[95 \% \mathrm{CI}]$} & \multirow{2}{*}{$\begin{array}{l}P \text { value } \\
<0.001\end{array}$} \\
\hline & & 3.370 & 9.108 & \\
\hline Blacks $^{\mathrm{a}}$ & 1.133 & 0.808 & 1.588 & 0.464 \\
\hline Female $^{\mathrm{b}}$ & 1.123 & 0.853 & 1.479 & 0.403 \\
\hline Age & 0.999 & 0.994 & 1.004 & 0.761 \\
\hline \multicolumn{5}{|l|}{ Education $^{\mathrm{c}}$} \\
\hline 12 years & 1.420 & 1.122 & 1.798 & 0.004 \\
\hline $13-15$ years & 1.926 & 1.492 & 2.485 & $<0.001$ \\
\hline 16 years or more & 2.385 & 1.748 & 3.254 & $<0.001$ \\
\hline \multicolumn{5}{|l|}{ Region $^{\mathrm{d}}$} \\
\hline Midwest & 1.132 & 0.913 & 1.404 & 0.253 \\
\hline South & 1.113 & 0.936 & 1.323 & 0.221 \\
\hline West & 1.039 & 0.650 & 1.661 & 0.871 \\
\hline Obesity\# Blacks & 0.625 & 0.411 & 0.949 & 0.028 \\
\hline Obesity\# Female & 1.967 & 1.401 & 2.761 & $<0.001$ \\
\hline Intercept & 0.183 & 0.131 & 0.255 & $<0.001$ \\
\hline
\end{tabular}

${ }^{\text {a }}$ Reference group; Whites

${ }^{\mathrm{b}}$ Reference group; Whites

${ }^{\mathrm{c}}$ Reference group; 11 years or less

${ }^{\mathrm{d}}$ Reference group; northeast literature that suggests that women are more health conscious than men [34].

Our results suggest that individuals with obesity have body dissatisfaction and want to engage in weight management behaviors that may lower their weight. Although not studied here, such behaviors include an increased intake of fruits and vegetables, or reduction in intake of high calorie foods, or an increase in exercise and physical activity $[35,36]$. Future research should test if race and gender influence the behavioral translation of intention as well.

Culture may influence how life style factors such as unhealthy diet and physical inactivity contribute to excess weight [37]. Our information, however, is limited on how pathways with end results of obesity and metabolic syndromes among minority groups. Additionally, very few data exists on how Blacks and Whites differ in complex ways by which their attitude about self and weight perception inform weightrelated behaviors [38]. Thomas posits that among ethnic minorities, historical, social, and cultural forces affect how attitudes and perceptions determine the lifestyle behaviors that translate to obesity [39].

This study adds to the existing knowledge on gender and race differences [40-53] particularly the effect of obesity on intention for weight loss [54-57]. Based on psychological theories such as reasoned action and planned behavior, however, intention is the strongest predictor of behaviors [58-60]. The associations between actual weight, weight perception, body dissatisfaction, weight loss intention, weight loss behaviors, and mental health are complex and may be under the influence of race, gender, ethnicity, and their intersections [61-65].

Our results may have important public implications for health promotion of over-weight and obese individuals [66]. Thus, universal healthy weight programs may have lower efficacy, unless the intervention program designs are informed by factors that explain predictors of weight specifically in each population.

Our findings suggest that healthy weight programs should be tailored based on race and gender of the target individual [67]. Future research should test if such tailoring increases the efficacy of healthy weight programs among minorities. This is critical as even modest weight loss may lower risk of coronary heart disease, hypertension, diabetes, hyperlipidemia, cardiorespiratory failure, and several other chronic diseases $[68,69]$.

Over $60 \%$ of the US population is either overweight or obese [70-72]. Causing approximately 300,000 deaths each year, obesity is only second to cigarette smoking as the leading cause of death [73]. With the current trend for obesity [74], an increase in the obesity-related mortality and morbidity is expected in the near future [75]. These findings are particularly important because the existing trend in the epidemic of obesity has been attributed to the increase in unhealthy lifestyle rather than genetics $[70,71]$. These concerns have 
increased the attention of public health authorities to programs that promote weight loss intention among obese individuals [76].

Our findings may have important implications for healthy weight interventions and weight reduction programs among minority populations in the USA. While obesity increases mortality rates from all causes, and especially CVD by 50 to $100 \%$ [77], even small weight loss reduces the risk of complications associated with obesity. Fortunately, even the beneficial effects of minimal weight loss will be significant [78].

Our study had a few limitations. A single item was used to measure intention for weight loss. Obesity was measured using self-reported data on weight and height. Although social norms and normative beliefs may predict intentions for weight control [80], we did not measure social norms related to thinness or obesity [79]. In addition, we used data from the National Survey of American Life, which was collected more than a decade ago, as obtaining more recent data was not possible. Finally, intention to lose weight but not the weight loss itself was the outcome [81]. Large sample size and nationally representative sample were two major strengths of this study.

In summary, gender and race change the link between obesity and intention to lose weight. The association between obesity and weight loss intention seems to be stronger among women and Whites than men and Blacks, respectively.

Conflict of interest Shervin Assari and Maryam Moghani Lankarani declare that they do not have any conflicts of interest.

Shervin Assari designed the work, analyzed the data, and drafted the manuscript. Maryam Moghani Lankarani contributed to the manuscript drafting and revision.

Publicly available data has been used. Informed consent was obtained from all individual participants included in the study. All procedures performed in studies involving human participants were in accordance with the ethical standards of the institutional and/or national research committee and with the 1964 Helsinki declaration and its later amendments or comparable ethical standards.

The NSAL is mostly supported by the National Institute of Mental Health, with grant U01-MH57716. Other support came from the Office of Behavioral and Social Science Research at the National Institutes of Health and the University of Michigan. For this analysis, public data set was downloaded from Interuniversity Consortium for Political and Social Research (ICPSR), Institute for Social Research at University of Michigan.

\section{References}

1. Klein S, Burke LE, Bray GA, Blair S, Allison DB, Pi-Sunyer X, et al. American Heart Association Council on Nutrition, Physical Activity, and Metabolism. Clinical implications of obesity with specific focus on cardiovascular disease: a statement for professionals from the American Heart Association Council on Nutrition, Physical Activity, and Metabolism: endorsed by the American College of Cardiology Foundation. Circulation. 2004;110(18):2952-67.
2. Reis JP, Loria CM, Lewis CE, Powell-Wiley TM, Wei GS, Carr JJ, et al. Association between duration of overall and abdominal obesity beginning in young adulthood and coronary artery calcification in middle age. JAMA. 2013;310(3):280-8. doi:10.1001/jama.2013. 7833.

3. Landsberg L, Aronne LJ, Beilin LJ, Burke V, Igel LI, Lloyd-Jones $\mathrm{D}$, et al. Obesity-related hypertension: pathogenesis, cardiovascular risk, and treatment: a position paper of The Obesity Society and the American Society of Hypertension. J Clin Hypertens (Greenwich). 2013;15(1):14-33.

4. Mokdad AH, Ford ES, Bowman BA, Dietz WH, Vinicor F, Bales VS, et al. Prevalence of obesity, diabetes, and obesity-related health risk factors, 2001. JAMA. 2003;289(1):76-9.

5. Ruland S, Hung E, Richardson D, Misra S, Gorelick PB, African American Antiplatelet Stroke Prevention Study Investigators. Impact of obesity and the metabolic syndrome on risk factors in African American stroke survivors: a report from the AAASPS. Arch Neurol. 2005;62(3):386-90.

6. Kurth T, Gaziano JM, Berger K, Kase CS, Rexrode KM, Cook NR, et al. Body mass index and the risk of stroke in men. Arch Intern Med. 2002;162(22):2557-62.

7. Andreyeva T, Sturm R, Ringel JS. Moderate and severe obesity have large differences in health care costs. Obes Res. 2004;12(12):1936-43.

8. Finkelstein EA, Ruhm CJ, Kosa KM. Economic causes and consequences of obesity. Annu Rev Public Health. 2005;26:239-57.

9. Tunceli K, Li K, Williams LK. Long-term effects of obesity on employment and work limitations among U.S. Adults, 1986 to 1999. Obesity (Silver Spring). 2006;14(9):1637-46.

10. Yancey AK, Simon PA, McCarthy WJ, Lightstone AS, Fielding JE. Ethnic and sex variations in overweight self-perception: relationship to sedentariness. Obesity (Silver Spring). 2006;14(6):980-8.

11. Surgeon General. Overweight and obesity: health consequences the surgeon general's call to action to prevent and decrease overweight and obesity http://www.surgeon general.gov/topics/obesity/ calltoaction/factsheet03.pdf

12. DivisionofAdultandCommunityHealth,NCfCDPaHP,Centers for Disease Control and Prevention, Behavioral Risk Factor Surveilance System Online Prevalence Data, www.cdc.gov,22 January

13. Striegel-Moore RH, Wilfley DE, Caldwell MB, Needham ML, Brownell KD. Weight-related attitudes and behaviors of women who diet to lose weight: a comparison of black dieters and white dieters. Obes Res. 1996;4(2):109-16.

14. Carroll SL, Lee RE, Kaur H, Harris KJ, Strother ML, Huang TT. Smoking, weight loss intention and obesity-promoting behaviors in college students. J Am Coll Nutr. 2006;25(4):348-53.

15. Lee RE, Harris KJ, Catley D, Shostrom V, Choi S, Mayo MS, et al. Factors associated with BMI, weight perceptions and trying to lose weight in African-American smokers. J Natl Med Assoc. 2005;97(1):53-61.

16. Johnson JL, Eaton DK, Pederson LL, Lowry R. Associations of trying to lose weight, weight control behaviors, and current cigarette use among US high school students. J Sch Health. 2009;79(8): 355-60.

17. McNutt SW, Hu Y, Schreiber GB, Crawford PB, Obarzanek E, Mellin L. A longitudinal study of the dietary practices of black and white girls 9 and 10 years old at enrollment: the NHLBI Growth and Health Study. J Adolesc Health. 1997;20(1):27-37.

18. Gavin 3rd JR, Fox KM, Grandy S. Race/Ethnicity and gender differences in health intentions and behaviors regarding exercise and diet for adults with type 2 diabetes: a cross-sectional analysis. BMC Public Health. 2011;11:533. doi:10.1186/1471-2458-11-533.

19. August KJ, Sorkin DH. Racial/ethnic disparities in exercise and dietary behaviors of middle-aged and older adults. J Gen Intern Med. 2011;26(3):245-50. doi:10.1007/s11606-010-1514-7. 
20. Davis EM, Clark JM, Carrese JA, Gary TL, Cooper LA. Racial and socioeconomic differences in the weight-loss experiences of obese women. Am J Public Health. 2005;95(9):1539-43.

21. Dorsey RR, Eberhardt MS, Ogden CL. Racial and ethnic differences in weight management behavior by weight perception status. Ethn Dis. 2010;20(3):244-50.

22. Paeratakul S, White MA, Williamson DA, Ryan DH, Bray GA. Sex, race/ethnicity, socioeconomic status, and BMI in relation to self-perception of overweight. Obes Res. 2002;10(5):345-50.

23. James DC. Gender differences in body mass index and weight loss strategies among African Americans. J Am Diet Assoc. 2003;103(10):1360-2.

24. Assari S. Perceived overweight mediates the association between obesity and intention for weight control among white women and black men but not white men and black women. Int J Prev Med. 2014. Under review.

25. Jackson JS, Neighbors HW, Nesse RM, Trierweiler SJ, Torres M. Methodological innovations in the National Survey of American Life. Int J Methods Psychiatr Res. 2004;13:289-98.

26. Heeringa S, Wagner J, Torres M, Duan N, Adams T, Berglund P. Sample Designs and Sampling Methods for the Collaborative Psychiatric Epidemiology Studies (CPES). Int J Methods Psychiatr Res. 2004;13(4):221-39.

27. Gavin AR, Rue T, Takeuchi D. Racial/ethnic differences in the association between obesity and major depressive disorder: findings from the Comprehensive Psychiatric Epidemiology Surveys. Public Health Rep. 2010;125(5):698-708.

28. Taylor AW, Dal Grande E, Gill TK, Chittleborough CR, Wilson $\mathrm{DH}$, Adams RJ, et al. How valid are self-reported height and weight? A comparison between CATI self-report and clinic measurements using a large cohort study. Aust N Z J Public Health. 2006;30(3):238-46.

29. Simon GE, Von Korff M, Saunders K, Miglioretti DL, Crane PK, van Belle $G$, et al. Association between obesity and psychiatric disorders in the US adult population. Arch Gen Psychiatry. 2006;63(7):824-30.

30. Assari S. Association between obesity and depression among American Blacks: role of ethnicity and gender. J Racial Ethnic Health Disparities. 2014. doi:10.1007/s40615-014-0007-5.

31. Assari S. Additive effects of anxiety and depression on body mass index among Blacks: role of ethnicity and gender. Int Cardiovasc Res J. 2014. In Press.

32. American Dietetic Association: American's Food and Nutrition Attitudes and Behaviors-American Dietetic Association's Nutrition and You: Trends 2000. Available on-line May 25,2005: http://www.eatright.org/Public/Media/PublicMedia_10333.cfm.

33. Rand CSW, Resnick JL. The "good enough" body size as judged by people of varying age and weight. Obes Res. 2000;8:309-16.

34. Parmenter K, Waller J, Wardle J. Demographic variation in nutrition knowledge in England. Health Educ Res. 2000;15(2):163-74.

35. Heinberg L. Body image dissatisfaction as a motivator for healthy lifestyle change: is some distress beneficial? Washington DC: American Psychological Association; 2001.

36. Neumark-Sztainer D, Paxton SJ, Hannan PJ, Haines J, Story M. Does body satisfaction matter? Five-year longitudinal associations between body satisfaction and health behaviors in adolescent females and males. J Adolesc Health. 2006;39(2):244-51.

37. Boyington JE, Carter-Edwards L, Piehl M, Hutson J, Langdon D, McManus S. Cultural attitudes toward weight, diet, and physical activity among overweight African American girls. Prev Chronic Dis. 2008;5(2):A36.

38. Blixen CE, Singh A, Thacker H. Values and beliefs about obesity and weight reduction among African American and Caucasian women. J Transcult Nurs. 2006;17(3):290-7.

39. Thomas VG. Using feminist and social structural analysis to focus on the health of poor women. Women Health. 1994;22(1):1-15.
40. Assari S, Caldwell C. Gender and Ethnic Differences in the Association between Obesity and Depression among Black Adolescents. J Racial Ethnic Health Disparities. 2015. doi:10. 1007/s40615-015-0096-9.

41. Assari S. Chronic medical conditions and major depressive disorder: differential role of positive religious coping among African Americans, Caribbean Blacks and non-Hispanic Whites. Int J Prev Med. 2014;5(4):405-13.

42. Assari S. Race and ethnicity, religion involvement, church-based social support and subjective health in United States: a case of moderated mediation. Int J Prev Med. 2013;4(2):208-17.

43. Assari S. Separate and Combined Effects of Anxiety, Depression and Problem Drinking on Subjective Health among Black, Hispanic and Non-Hispanic White Men. Int J Prev Med. 2014;5(3):269-79.

44. Assari S, Lankarani MM, Lankarani RM. Ethnicity Modifies the Additive Effects of Anxiety and Drug Use Disorders on Suicidal Ideation among Black Adults in the United States. Int J Prev Med. 2013;4(11):1251-7.

45. Assari S. The link between mental health and obesity: role of individual and contextual factors. Int J Prev Med. 2014;5(3):247-9.

46. Assari S. Race and Ethnic Differences in Associations between Cardiovascular Diseases, Anxiety, and Depression in the United States. Int J Travel Med Global Health. 2014;2(3):103-9.

47. Assari S, Moghani Lankarani M, Kazemi Saleh D. Ahmadi K Gender modifies the effects of education and income on sleep quality of the patients with coronary artery disease. Int Cardiovasc Res J. 2013;7(4):141-6.

48. Assari S, Caldwell CH, Zimmerman MA. Sex differences in the association between testosterone and violent behaviors. Trauma Monthly. 2014;19(3), e18040.

49. Assari S, Watkins D, Caldwell CH. Multiplicative effect of discrimination and race attribution on depression among blacks: the role of gender and ethnicity. J Racial Ethnic Health Dispar. 2014;1(3):1-8.

50. Assari S. Chronic kidney disease, anxiety and depression among American blacks; Does ethnicity matter? Int J Travel Med Glob Health. 2014;2(4):133-9.

51. Tavallaii SA, Fathi-Ashtiani A, Nasiri M, Assari S, Maleki P, Einollahi B. Correlation between sexual function and postrenal transplant quality of life: does gender matter? J Sexual Med. 2007;4(6):1610-8.

52. Khooshabi K, Ameneh-Forouzan S, Ghassabian A, Assari S. Is there a gender difference in associates of adolescents' lifetime illicit drug use in Tehran, Iran? Arch Med Sci: AMS. 2010;6(3):399-406.

53. Assari S. Depression Mediates the Effect of Sexual Function on Quality of Life among Men but Not Women with Coronary Artery Disease. Int Cardiovasc Res J. 2014;8(4):171-7.

54. Greenberg DR, LaPorte DJ. Racial differences in body type preferences of men for women. Int J Eat Disord. 1996;19(3):275-8.

55. Powell AD, Kahn AS. Racial differences in women's desires to be thin. Int J Eat Disord. 1995;17(2):191-5.

56. Kumanyika S, Wilson JF, Guildford-Davenport M. Weight related attitudes and behaviors of black women. J Am Diet Assoc. 1993;93(4):416-22.

57. Parker S, Nichter M, Nichter M, Vuckovic N, Sims C, Ritenbaugh C. Body image and weight concerns among African-American and white adolescent females: differences that make a difference. Hum Organ. 1995;54(2):103-14.

58. Ajzen I. From intentions to actions: a theory of planned behavior. In: Kuhl J, Beckman J, editors. Action-control: from cognition to behavior. Heidelberg: Springer; 1985. p. 11-39.

59. Ajzen I. The theory of planned behavior. Organ Behav Hum Decis Process. 1991;50:179-211.

60. Hale JL, Householder BJ, Greene KL. The theory of reasoned action. In: Dillard JP, Pfau M, editors. The persuasion handbook: 
developments in theory and practice. Thousand Oaks: Sage; 2003. p. $259-86$.

61. Brener ND, Eaton DK, Lowry R, McManus T. The association between weight perception and BMI among high school students. Obes Res. 2004;12(11):1866-74.

62. Story M, Stevens J, Evans M, Cornell CE, Juhaeri, Gittelsohn J, et al. Weight loss attempts and attitudes toward body size, eating, and physical activity in American Indian children: relationship to weight status and gender. Obes Res. 2001;9(6):356-63.

63. Viner RM, Haines MM, Taylor SJ, Head J, Booy R, Stansfeld S. Body mass, weight control behaviours, weight perception and emotional well being in a multiethnic sample of early adolescents. Int $\mathbf{J}$ Obes (Lond). 2006;30(10):1514-21.

64. Forman-Hoffman V. High prevalence of abnormal eating and weight control practices among U.S. high-school students. Eat Behav. 2004;5(4):325-36.

65. Bish CL, Blanck HM, Serdula MK, Marcus M, Kohl 3rd HW, Khan LK. Diet and physical activity behaviors among Americans trying to lose weight: 2000 Behavioral Risk Factor Surveillance System. Obes Res. 2005;13(3):596-607.

66. Hawkins DS, Hornsby PP, Schorling JB. Stages of change and weight loss among rural African American women. Obes Res. 2001;9(1):59-67.

67. Bronner Y, Boyington JE. Developing weight loss interventions for African-American women: elements of successful models. J Natl Med Assoc. 2002;94(4):224-35.

68. Pasanisi F, Contaldo F, de Simone G, Mancini M. Benefits of sustained moderate weight loss in obesity. Nutr Metab Cardiovasc Dis. 2001;11(6):401-6.

69. Gregg EW, Gerzoff RB, Thompson TJ, Williamson DF. Trying to lose weight, losing weight, and 9-year mortality in overweight U.S. adults with diabetes. Diabetes Care. 2004;27(3):657-62.
70. Must A, Spadano J,CoakleyEH, et al. The disease burden associated with over weight and obesity. JAMA. 199; 282: 1523-1529.

71. Flegal KM, Troiano, RP. Changes in the distribution of body mass index of adults and children in the U.S. population. Int J Obes Relat Metab Disord. 200;24:807-818.

72. Mokdad AH, Serdula MK, Dietz WH, Bowman BA, Marks JS, Koplan JP. The spread of the obesity epidemic in the United States, 1991-1998. JAMA. 1999;282:1519-22.

73. McGinnis JM, Foege WH. Actual causes of death in the United States. JAMA. 1993;270:2207-12.

74. Mokdad AH, Serdula MK, Dietz WH, et al. The spread of the obesity epidemic in the United States, 1991-1998. JAMA. 199;282:1519-2.

75. Prevalence of overweight among adolescents - United States, 1988-91. MMWR Morb Mortal Wkly Rep. 1994;43:818-21.

76. Anderson JW, Luan J, Høie LH. Structured weight-loss programs: meta-analysis of weight loss at 24 weeks and assessment of effects of intervention intensity. Adv Ther. 2004;21(2):61-75.

77. Poirier P, Després JP. Exercise in weight management of obesity. Cardiol Clin. 2001;19(3):459-70.

78. Klein S. Outcome success in obesity. Obes Res. 2001;9 Suppl 4: 354S-8S.

79. Saarni S, Silventoinen K, Rissanen A, Sarlio-La'hteenkorva S, Kaprio J. Intentional weight loss and smoking in young adults. Int J Obes. 2004;28:796-802.

80. Leahey TM, Gokee LaRose J, Fava JL, Wing RR. Social influences are associated with BMI and weight loss intentions in young adults. Obesity (Silver Spring). 2011;19(6):1157-62.

81. Schifter DE, Ajzen I. Intention, perceived control, and weight loss: an application of the theory of planned behavior. J Pers Soc Psychol. 1985;49(3):843-51. 